\title{
MEMBANGUN ENGAGEMENT MELALUI PLATFORM DIGITAL (STUDI KASUS FLIP SEBAGAI START-UP FINTECH)
}

\author{
Intan Putri Cahyani \\ Prodi IImu Komunikasi FISIP UPN Veteran Jakarta
}

Naskah diterima tanggal 21-04-2020, direvisi tanggal 13-06-2020, disetujui tanggal 17-06-2020

\begin{abstract}
Abstrak. Hadir sebagai start-up lokal, Flip memberi warna baru di dunia FinTech (Financial Technology) dengan layanan transfer antar bank bebas biaya admin. Flip sadar bahwa berkomunikasi dengan target audiens sangat penting. Saat ini Flip telah memiliki website dan media sosial yang dikelola dalam membangun digital engagement. Peneliti tertarik untuk melakukan studi tentang bagaimana Flip sebagai start-up local di bidang FinTech membangun digital engagement melalui berbagai aktivitas Public Relations di berbagai platform. Tipe penelitian ini merupakan studi deskriptif kualitatif dengan metode studi kasus. Pengumpulan data dilakukan melalui (1) website dan social media monitoring dan (2) wawancara mendalam. Hasil penelitian menunjukkan bahwa Flip sangat menyadari komunikasi berperan penting dalam sustainability business. Flip telah menggunakan platform digital untuk menyampaikan segala sesuatu yang baru tentang produk mereka, sekaligus membentuk mutual understanding melalui percakapan yang dibangun. Dengan segala keterbatasan sumber daya yang dimiliki, peringkat website flip.id telah meningkat $32 \%$ selama periode Januari - Maret 2020 . Konten yang mendapatkan engagement tertinggi antara lain giveaway, tips dan challenge sedangkan Instagram menjadi media sosial dengan rata-rata engagement tertinggi mencapai $60 \%$. Berbagai aktivitas online Flip dimetaforakan selayaknya pertemanan dimana mereka berusaha hadir untuk memberikan manfaat. Flip juga bekerja sama dengan Social Media Influencer (SMI) berupa Micro Influencer yang memiliki keahlian di bidang keuangan dengan follower yang segmented dan terbukti cukup efektif dalam membangun engagement.
\end{abstract}

Kata kunci: public relations, start-up, FinTech, digital engagement, media sosial

\begin{abstract}
Present as a local start-up, Flip has given a new color to the world of FinTech (Financial Technology) with an admin-free interbank transfer service. Flip is aware that communicating with the target audience is very important. Currently Flip already has a website and social media that are managed in building digital engagement. Researchers are interested in conducting a study of how Flip as a local start-up in the FinTech field builds digital engagement through various Public Relations activities on various platforms. This type of research is a qualitative descriptive study with a case study method. Data collection is done through (1) website and social media monitoring and (2) in-depth interviews. The results show that Flip understands communication plays an important role in business sustainability. Flip has used a digital platform to convey everything new about its products, as well as forming mutual understanding through conversations that are built. With all the limited resources available, flip.id website ranking has increased by $32 \%$ between January and March 2020. Content that gets the highest engagement includes a giveaway, tips, and challenges while Instagram becomes social media with the highest average engagement reaching $60 \%$. Flip's various online activities are termed as friendships where they try to be present to provide benefits. Flip also collaborates with Social Media Influencer (SMI) in the form of Micro-Influencers who have expertise in finance with segmented followers and are proven to be quite effective in building engagement.
\end{abstract}

Keywords: public relations, start-up, FinTech, digital engagement, social media 


\section{PENDAHULUAN}

Perkembangan teknologi di era internet of things (IoT) memudahkan bagi siapa saja untuk mendapatkan akses dalam berbagai sektor, termasuk sektor Financial Technology atau lebih sering disebut FinTech. Berbagai manfaat yang didapatkan berupa layanan keuangan dengan biaya marjinal di bawah operator tradisional membuat para konsumen berpaling untuk menggunakan layanan tersebut. Industri FinTech menawarkan model bisnis baru baik P2P, $\mathrm{B} 2 \mathrm{C}$, ataupun B2B untuk kegiatan keuangan tradisional, seperti pengumpulan dan peminjaman dana, investasi dan perdagangan saham, koin digital, uang elektronik dan komoditas lainnya (Natalia \& Shihab, 2018). Pendekatan transformatif untuk menyediakan layanan keuangan ini cukup fleksibel untuk diadopsi oleh pasar yang kurang terjangkau atau baru. Negara-negara berkembang seperti Indonesia, termasuk yang paling terdepan dalam mengadopsi layanan FinTech bahkan lebih cepat daripada negara-negara maju (Arner et al., 2015).

Konsisten dengan teori ekonomi, gabungan elemen FinTech, yaitu, teknologi dan jasa keuangan, memberikan dorongan untuk pertumbuhan ekonomi. Terdapat bukti empiris bahwa, di Indonesia, FinTech memiliki kapasitas untuk mengurangi inflasi dan memperkuat rupiah terhadap dolar AS (Narayan dan Sahminan, 2018). FinTech juga memberikan efek positif pada pengembalian bank serta menyiratkan hubungan komplementer antara bank tradisional dan FinTech (Li et al., 2017).

Hadir sebagai start-up local kreasi anak bangsa, Flip memberikan warna baru di dunia FinTech (Financial Technology) dengan menyediakan aplikasi untuk melakukan transfer antar bank bebas biaya admin yang bisa diakses melalui perangkat Android dan IOS. Berada di bawah naungan PT Fliptech Lentera Inspirasi Pertiwi, Flip bekerja sebagai jembatan transaksi antar bank dan telah mendapatkan lisensi dari Bank Indonesia pada tanggal 4 Oktober 2016 dengan nomor izin 18/196/DKSP/68 (flip.id, 2020).

Hingga pertengahan April 2020, Aplikasi Flip telah digunakan oleh lebih dari 1 juta pengguna dan mendapatkan rating 4.4 di Google PlayStore. Dengan pencapaian tersebut, Flip membuktikan bahwa sebagai start-up local dalam 4 tahun terakhir Flip cukup diminati.

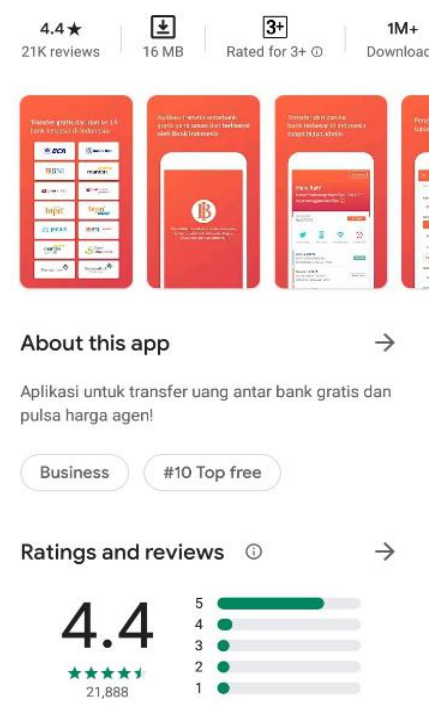

Gambar 1. Rating Aplikasi Flip

Sumber : Google Playstore, April 2020

Tidak hanya berfokus pada pengembangan core business yang dijalankan, Flip juga berusaha untuk bisa berkomunikasi dan lebih dekat dengan target audiens. Saat ini Flip telah memiliki website dan media sosial yang dikelola dalam membangun digital engagement serta bagian dari PR tools yang mereka gunakan. Media sosial menduduki posisi teratas layanan yang paling banyak diakses melalui internet setelah aplikasi chatting. Melalui media sosial memungkinkan para pengguna untuk membuat sekaligus berbagi konten yang berisi 
informasi, opini, dan minat dalam konteks yang beragam (Khan, 2017). Media sosial yang dimiliki oleh Flip antara lain Instagram, Twitter, Facebook, dan LINE.

Dengan fitur inheren dua arah, interaktif, komunal, dan relasional, media sosial telah memberikan peluang besar bagi organisasi untuk melibatkan multi stakeholder dan membangun hubungan jangka panjang dengan mereka (Saxton \& Waters, 2012). Dalam komunikasi strategis, khususnya Public Relations, sejumlah penelitian telah dilakukan untuk menguji penggunaan media sosial yang efektif dalam keterlibatan stakeholder untuk berbagai jenis organisasi termasuk perusahaan, organisasi nirlaba, dan lembaga pemerintah (Avery \& Graham, 2013). Studi sebelumnya telah menunjukkan efek positif dari keterlibatan media sosial pada hasil persepsi, relasional, dan perilaku para stakeholder serta pada bottom line bisnis dalam pengaturan organisasi yang berbeda (Li et al., 2017).

Namun, sayangnya sebagian besar dari studi tersebut dilakukan di lingkungan organisasi yang sudah mapan. Masih sedikit yang mengeksplorasi penggunaan strategis media sosial untuk keterlibatan stakeholder bagi perusahaan pemula (start-up). Perusahaan start-up sangat penting untuk pertumbuhan ekonomi di masyarakat modern. Semakin banyaknya start-up bermunculan menandakan adanya iklim bisnis yang sehat dan potensi pertumbuhan ekonomi yang positif (Chen et al., 2017). Berbeda dengan perusahaan besar yang cenderung sudah mapan dari berbagai hal, perusahaan start-up memiliki karakteristik unik. Sebagai contoh, sumber daya biasanya terbatas dan identitas perusahaan, reputasi, dan struktur internal belum dibangun di start-up (Bresciani \& Eppler, 2010). Karakteristik khusus ini menunjukkan pentingnya perusahaan pemula untuk mengembangkan strategi kreatif dan inovatif dalam komunikasi strategis dan praktik branding mereka, daripada mengikuti pedoman yang disediakan untuk perusahaan besar (Boyle, 2003). Media sosial sebagai tools yang relatif hemat biaya dapat dimanfaatkan oleh perusahaan start-up untuk membangun identitas perusahaan dan stakeholder engagement.

Bruce dan Shelley (2010) mendefinisikan stakeholder engagement sebagai interaksi antara organisasi dan individu dan kelompok yang dipengaruhi oleh, atau mempengaruhi organisasi. Selama proses engagement, baik organisasi dan stakeholder bersama-sama mengelola hubungan dan membangun makna untuk mencapai kesepakatan dan tujuan yang saling menguntungkan (Botan \& Taylor, 2004; Heath, 2014).

Meskipun dalam berbagai konteks penelitian, engagement ditafsirkan dengan fokus utama yang berbeda (misalnya, keterlibatan masyarakat, keterlibatan politik, dll.), Para peneliti telah mencapai konsensus umum bahwa komunikasi dalam stakeholder engagement harus beralih dari komunikasi satu arah ke interaksi dua arah. (Devin \& Lane, 2014). Engagement sebagai strategi komunikasi dua arah dan relasional melibatkan dan menguntungkan semua pihak yang berkepentingan melalui peningkatan pemahaman antara organisasi dan berbagai stakeholder terkait (Heath, 2006)

Engagement ini sangat penting bagi seorang PR sebagai dasar strategi komunikasi jangka panjang untuk menuju positioning dan reputasi yang diinginkan perusahaan (Natalia \& Shihab, 2018). Digitalisasi bukan hanya sekedar memindahkan proses bisnis, tapi menunjukkan komitmen perusahaan dengan meningkatkan layanan menjadi lebih sederhana dan mudah untuk digunakan serta dijangkau audiens. Pelanggan saat ini tidak hanya peduli tentang apa yg mereka beli (produk dan jasa) dan dari siapa mereka membelinya (brand) tetapi juga bagaimana mereka dapat membeli (experience). Pendekataan engagement mengharuskan brand menciptakan pengalaman yg konsisten untuk pelanggannya mengingat sekarang ini orang membeli pengalaman, bukan hanya barang ataupun jasa. Dimana untuk bertemu dengan pelanggan dimanapun mereka berada, brand perlu memberikan pengalaman pelanggan yg terintegrasi di setiap platform atau dengan kata lain brand harus menyediakan omni-platform yang bisa diakses oleh target audiensnya (Lovejoy et al., 2012)

Hingga saat ini, masih minim sekali penelitian bidang komunikasi yang meneliti tentang praktik Digital PR yang dilakukan oleh industri FinTech, sehingga peneliti tertarik untuk meneliti tentang bagaimana Flip sebagai start-up lokal di bidang FinTech membangun digital engagement melalui berbagai aktivitas Public Relations di berbagai platform digital seperti website dan media sosial. 


\section{METODE PENELITIAN}

Tipe penelitian ini adalah deskriptif kualitatif dengan metode studi kasus. Jenis penelitian ini memiliki tujuan untuk mendeskripsikan dan menarasikan berbagai fakta dan sifat populasi atau objek tertentu secara sistematis, mendalam dan akurat (Kriyantono, 2020).

Riset kualitatif memiliki prosedur riset dengan menjelaskan fenomena dengan sangat mendetail dan komprehensif melalui pengumpulan data sedalam-dalamnya yang selanjutnya disebut thick description. Dengan kata lain, penelitian ini lebih fous pada kedalaman (holistic/depth) daripada keluasan (breadth). Sedangkan studi kasus merupakan metode riset yang mengacu pada berbagai sumber data yang bisa dimanfaatkan dalam proses riset, menguraikan, dan menjelaskan secara detail dan mendalam tentang berbagai aspek individu, suatu kelompok, suatu organisasi (komunitas), suatu program, atau suatu situasi sosial. Dalam studi kasus, peneliti berupaya menganalisis sebanyak mungkin data mengenai subjek yang diteliti. Menggunakan berbabagai metode seperti wawancara, pengamatan, penelaahan dokumen, hasil survey dan data apapun untuk menguraikan suatu kasus secara terperinci namun komprehensif (Kriyantono 2020).

Terdapat memberikan batasan mengenai metode studi kasus sebagai riset untuk menyelidiki dan memeriksa fenomena di dalam konteks kehidupan nyata, jika terdapat batas antara fenomena dan konteks kurang terlihat tegas, dan dimana multisumber bukti dimanfaatkan (Yin 2006). studi kasus berusaha mempelajari, menerangkan, dan mengintepretasi suatu kasus dalam konteksnya yang alami tanpa intervensi pihak luar (Mulyana 2001).

Pengumpulan data penelitian ini dilakukan melalui metode (1) observasi melalui website dan social media monitoring dan (2) wawancara mendalam. Observasi ini dibutuhkan periset untuk mengamati aktivitas akun website dan media sosial yang digunakan oleh Flip dalam membangun engagement melalui aktivitas digital public relations. Kedua, metode wawancara mendalam, di mana peneliti melakukan kegiatan wawancara untuk menggali informasi dari key informan yaitu social media specialist dan product marketing specialist untuk mengkonfirmasi hal-hal yang ditemukan selama monitoring.

Dari data yang telah dikumpulkan, proses selanjutnya adalah analisis dan intepretasi data riset kualitatif. Tahap analisis data memegang peran penting dalam riset kualitatif, yaitu seebagai faktor utama penilaian kualitas tidaknya riset. Dalam riset kualitatif, menggunakan cara berpikir induktif, yaitu cara berpikir yang berangkat dari hal-hal khusus (fakta empiris) menuju hal-hal yang umum (tataran konsep).

Proses pertama yang dilakukan pada data yang sudah terkumpul adalah dengan melakukan pengklasififikasian atau kategorisasi dengan mempertimbangkan kesahihan data dan selanjutnya dilakukan pemaknaan terhadap data. Pemaknaan ini merupakan prinsip dasar riset kualitatif, yaitu bahwa realitas ada pada pikiran manusia, realitas adalah hasil konstruksi social manusia. Dalam proses ini, berteori penting untuk menghindari blocking interpretation. Pada tahap ini peneliti menjelaskan pola-pola hubungan antar data atau konsep sehingga mengandung makna tertentu (proposisi) secara teoritis, termasuk juga menjelaskan secara teori rancangan model baru, atau pemetaan model. Dari hasil proposi tersebut, termasuk di dalamnya rancangan model, teori baru, hasil pemetaan kemudian ditarik ke dalam simpulan riset (Kriyantono, 2020).

\section{HASIL PENELITIAN DAN PEMBAHASAN}

Flip mulai menggunakan media sosial sebagai medium komunikasi kepada user sejak 2015, tahun di mana flip didirikan. Alasan saat itu sangat sederhana, yaitu untuk menjangkau teman teman mahasiswa di lingkungan pertemanan para pendiri Flip. Twitter, Instagram, dan facebook adalah tiga platform yang cukup populer digunakan mahasiswa saat itu, khususnya Universitas Indonesia. Seiring dengan perkembangan bisnis Flip, mereka juga menyediakan 
website dan media sosial sebagai medium untuk menyampaikan segala sesuatu yang baru tentang Flip dengan membangun product knowledge dan brand awareness.

Namun, itu bukanlah hal yang utama. Flip sendiri menyadari bahwa tujuan komunikasi yang utama adalah membentuk mutual understanding melalui percakapan-percakapan yang dibangun di berbagai platform yang digunakan, khususnya media sosial. Oleh karena itu Flip ingin membangun digital engagement dimana user dapat berinteraksi dengan mereka di media sosial sekaligus mendapatkan manfaat berupa keilmuan dasar seputar dunia finansial, beragam tips keuangan yang lekat dengan keseharian mereka, serta menjalin hubungan dan kedekatan yang bersifat jauh lebih personal antara Flip sebagai perusahaan dengan konsumen dan/atau followers.

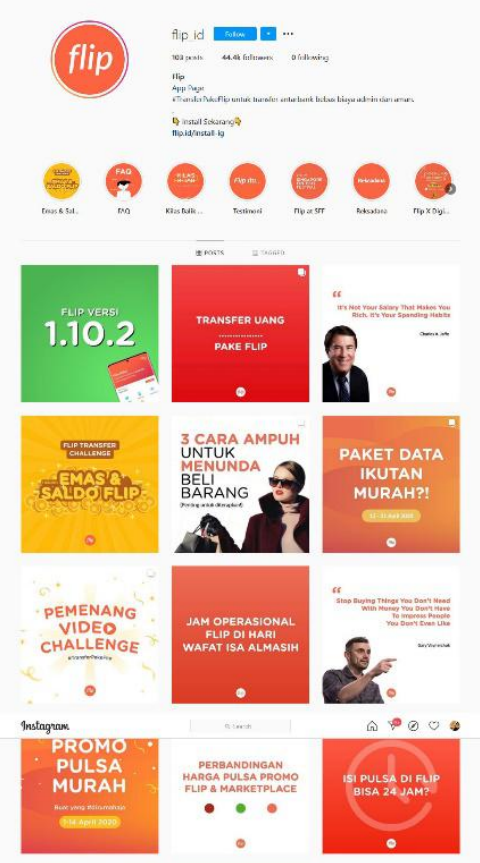

\section{Gambar 2. Brand Identity Flip dalam Feeds Instagram}

Sumber : Instagram Flip, April 2020

Di bawah bendera PT Fliptech Lentera Inspirasi Pertiwi, Flip menggunakan gradasi warna orange dan putih sebagai brand identity dan konsisten pada website maupun setiap media sosial. Berdasarkan hasil wawancara, Flip memposisikan dirinya sebagai partner dari banyak bank. Karena mayoritas bank menggunakan warna biru, maka Flip menggunakan warna oranye yang merupakan warna komplementer dari warna biru. Selain itu, energi yang dibawa Flip adalah kebaruan dan semangat. Hal ini sangat terwakilkan oleh warna oranye juga. Sedangkan warna putih biasa digunakan ketika menyampaikan informasi seputar dunia keuangan. Hal ini agar informasi terlihat lebih jelas dan user tak mudah lelah dalam membacanya karena biasanya informasi seputar dunia keuangan disampaikan dalam bentuk slide banner.

Berdasarkan daily monitoring yang dilakukan, tujuan dibuatnya website Flip sendiri adalah untuk memberikan informasi - informasi seputar penggunaan aplikasi Flip seperti cara penggunaan, cara kerja transfer, hingga nama - nama bank apa saja yang sudah bekerja sama dengan Flip. Di dalam website, tergambar dengan jelas alur transaksi saat menggunakan Flip. Alur ini dibuat untuk menjawab pertanyaan para pelanggan yang bertanya mengenai cara kerja transfer Flip. Penggunaan website flip.id ini biasanya didominasi oleh pengguna layanan big.flip.id. ada bagian dimana kita dapat melihat testimoni dari para pengguna Flip yang diambil dari beberapa konsumen Flip serta media coverage berisi liputan berbagai media tentang Flip. Website Flip juga menyertakan pertanyaan serta jawaban yang mungkin sering diajukan oleh 
konsumen Flip. Pertanyaan serta jawaban tersebut masuk ke dalam section FAQ (Frequently Asked Question). pada bagian bawah web, tertera informasi tambahan mengenai beberapa media sosial yang digunakan Flip untuk dapat lebih menjangkau penggunanya,jam layanan, serta apa saja yang berkaitan dengan perusahaan. Pada bagian ini juga ada kontak yang dapat dihubungi seperti email dan alamat perusahaan. Adapun media sosial tambahan yang digunakan adalah Instagram, Facebook, Twitter, serta LINE.

Berdasarkan hasil analytical tools, Peringkat website flip.id telah meningkat $32 \%$ selama 3 bulan terakhir (Januari - Maret 2020). Ini mencapai sekitar 63.330 pengunjung dengan 139.350 hits setiap bulan. Hal ini berarti, rata-rata setiap pengunjung melihat website sebanyak dua kali setiap bulan. Berdasarkan kata kunci yang sering digunakan dalam SEO, terdapat sekitar 82 kata dengan kata kunci Flip, Transfer Antar Bank, Biaya Transfer menduduki peringkat teratas.

Sebagai sebuah start-up bidang FinTech yang masih berumur jagung dan sempat mengalami kendala bisnis berupa Penutupan sementara oleh Bank Indonesia untuk mendapatkan izin legal beroperasi, Flip menentukan tujuan dari praktik Digital PR yang dilakukam secara bersama-sama antara tim marketing, CEO, dan Founder. Bagi Flip, salah satu indikator yang diukur adalah seberapa lama seseorang diam di website dan blog mereka untuk membaca dari satu artikel ke artikel lainnya, berapa jumlah share dan save dari setiap post, serta berapa besar tingkat presentasi interaksi yang terjalin dari masing-masing akun media sosial.
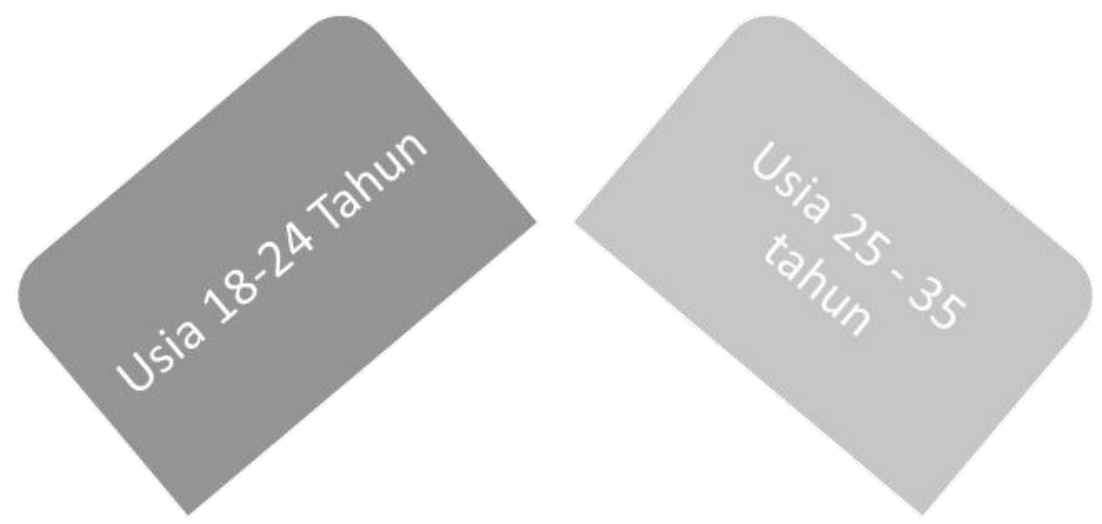

\section{Gambar 3. Usia Target Audiens Pengguna Media Komunikasi Flip \\ Sumber : Hasil Wawancara Key Informan}

Target audiens dari blog media sosial Flip adalah rentang usia 18 - 35 tahun yang tinggal di kota-kota besar di Indonesia. Rentang usia tersebut sebenarnya terbagi lagi ke dalam 2 kelompok usia, yaitu (1) kelompok usia $18-24$ tahun yang terdiri atas mahasiswa dan angkatan kerja baru (fresh entry level), dan (2) kelompok usia 25-35 tahun, mereka-mereka yang produktif yang telah mulai serius memikirkan karir dan berinventasi.

Kedua kelompok ini adalah kelompok usia yang pasti melakukan transfer antar bank dan keduanya adalah mindful spender. Psikografis kelompok pertama cenderung berhati hati dalam mengeluarkan biaya admin untuk berbagai transaksi yang dilakukan karena memiliki sumber daya yang masih minim, sedangkan psikografis kelompok yang satu lagi cenderung berhati hati karena mulai memikirkan masa depan (Ji et al., 2015).

Secara spesifik, Flip tidak menargetkan follower yang ingin dicapai, yang pasti mereka ingin terus menumbuhkan jumlah follower dengan menghadirkan banyak konten bermanfaat baik dari dalam internal flip maupun berkolaborasi dengan para ahli di bidang finansial dan bisnis. Bagi Flip bertambahnya jumlah follower sama dengan bertambahnya jumlah orang yang mendapat manfaat.

Dalam membuat sebuah konten, Flip memiliki brand guideline yang secara konsisten mereka jadikan acuan. Ada beberapa topik dan emosi yang harus disertakan dalam setiap konten. 


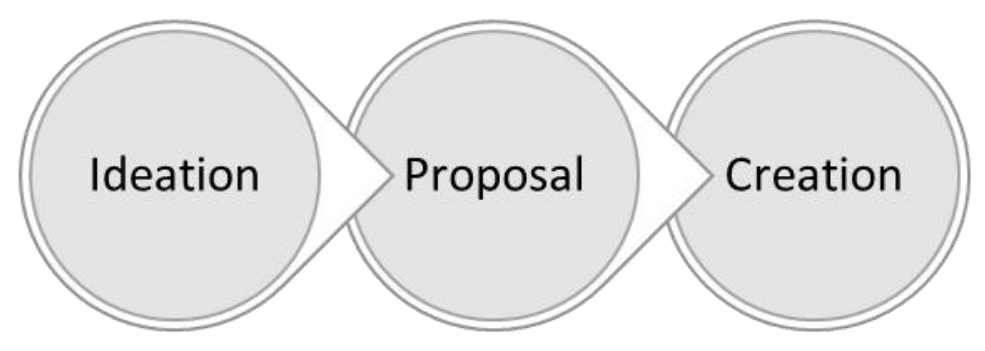

Gambar 4 . Proses pembuatan konten yang dilakukan Flip

Sumber : Hasil Wawancara Key Informan

Proses pembuatan sendiri secara garis besar melalui tiga tahapan yaitu Ideation Proposal - Creation. Dalam proses ideation, ada beberapa sumber yang menjadi landasan pembuatan konten seperti tren yang sedang terjadi, kebutuhan informasi internal yang ingin disampaikan, atau informasi yang sering ditanyakan oleh user maupun follower. Selanjutnya, ide diajukan ke tim dan ditempatkan ke dalam kalender konten setelah mendapatkan persetujuan. Untuk proses produksi draft konten akan dikerjakan oleh in house writer, sedangkan untuk produksi kebutuhan visual bisa dikerjakan oleh tim marketing maupun tim desain.

Keputusan tentang diunggah tidaknya sebuah konten serta waktu pengunggahan diputuskan secara bersama, Hal yang menjadi patokan Flip tentang waktu yang tepat untuk mengunggah sebuah konten baru adalah melalui data yang disediakan Instagram soal kapan followers kami aktif. Untuk blog tidak ada waktu tertentu karena bersifat organik dan timeless dari pencarian orang-orang di layanan pencarian google. Sedangkan untuk media sosial lain seperti twitter, Linkedin, dan tiktok masih dalam tahap riset. Terkait penunggahan konten, Flip melakukan penyesuaian bahasa dan jenis jenis konten apa saja yang diunggah dalam masing masing media sosial. Walaupun fasilitas autoconnect antar media sosial tidak digunakan, namun ada beberapa konten yang sama dengan tetap diberikan sentuhan penyesuaian konteks.

Berdasarkan hasil penelitian, secara garis besar konten yang ada di website dan media sosial Flip yaitu (1) Branding BIG Flip, Konten ini berisi branding BIG Flipyang merupakan fitur Flip sebagai solusi transfer untuk perusahaan, (2) Giveaway dan pengumuman pemenang. Flip seringkali mengadakan giveaway yang memberikan berbagai macam jenis hadiah, seperti uang berupa saldo Flip, pulsa, hingga smartphone, (3) Lowongan pekerjaan. Konten ini berisi pengumuman bahwa Flip sedang membuka lowongan pekerjaan yang disertai syarat dan ketentuan serta posisi yang ditawarkan, (4) Pemberitahuan update. Sebagai bentuk peningkatan kualitas layanan, Flip secara rutin mengupgrade aplikasinya agar konsumen dapat menikmati layanan yang diberikan secara lebih optimal, (5) Edukasi seputar finansial. Flip seringkali membuat konten berisi edukasi seputar finansial. Salah satu contohnya adalah mengenai beragam cara menabung yang bikin untung, (6) Polling hashtag. Flip membuka polling untuk dapat mengajak pengikutnya memilih hashtag yang cocok dipakai Flip dalam rangka menarik orang lain untuk memakai Flip, dan (7) Interaksi dengan pengikut. Flip sering kali berinteraksi di sosial media Twitter dengan pengikutnya. Tetapi untuk di sosial media yang lainnya kurang adanya interaksi Flip dengan pengikutnya.

Untuk kebutuhan marketing dan digital PR, mulai Maret 2020 tim Flip terdiri atas tiga orang dengan pembagian tugas yaitu satu orang menangani iklan digital untuk keperluan akuisisi user baru, satu orang fokus di konten organik (media sosial dan blog), satu orang fokus dalam branding secara offline. Saat ini Product Marketing Specialist juga diberikan wewenang untuk mengelola kanal pemasaran organik serta diberikan keleluasaan untuk membuat konten yang bermanfaat untuk user dengan berpedoman pada brand guideline yang dimiliki oleh Flip. 
Berdasarkan hasil analytical tools menggunakan Keyhole untuk media sosial Flip, saat ini Instagram flip_id memiliki jumlah pengikut sebanyak 42.198 orang dengan total unggahan yang menghiasi feed sebanyak 92 konten. Selama periode Januari hingga awal April 2020, Flip telah mengunggah 24 konten dengan jumlah digital engagement 25.674 atau $60,8 \%$ dan ratarata Engagement per unggahan adalah 1.069 .

Statistik Akun Flip per tanggal 7 Januari sampai 6 April 2020, menunjukkan bahwa jumlah unggahan paling produktif adalah bulan Maret dengan total post 17 namun engagement tertinggi yaitu pada bulan Februari dengan angka 3.982 dan rata - rata likes terbanyak pada bulan Februari sebanyak 3,446 begitu pula dengan rata - rata komen paling banyak pada bulan Februari dengan 536 komentar. Konten terbaik berdasarkan engagement adalah unggahan dengan bentuk giveaway, tips, dan Challenge. Hal tersebut relevan dengan hasil wawancara dimana menurut Key Informan ada beberapa tipe konten yang mendapatkan tingkat interaksi yang baik yaitu ilmu praktis seputar dunia keuangan, seperti cara menabung dan mengeola uang, giveaway, kuis, pengumuman fitur / benefit baru yang membantu konsumen, pertanyaan seputar diri user.

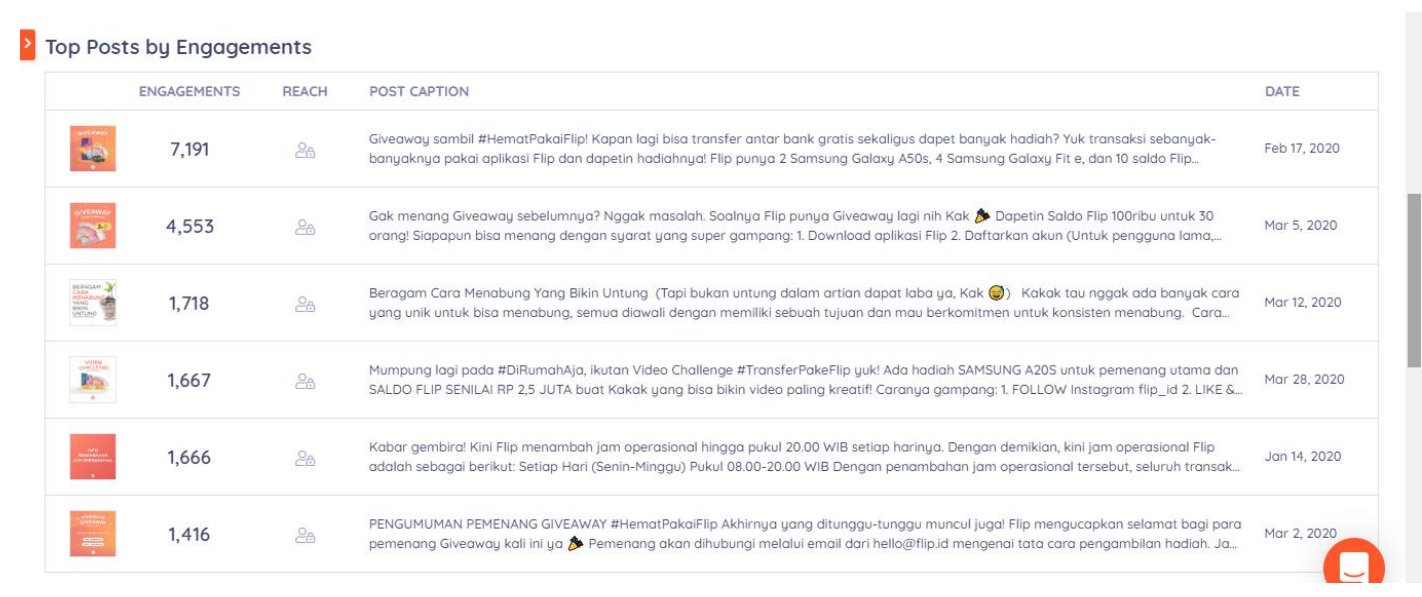

Gambar 5. Hasil Analytical Tools tentang Engagement Instagram Flip

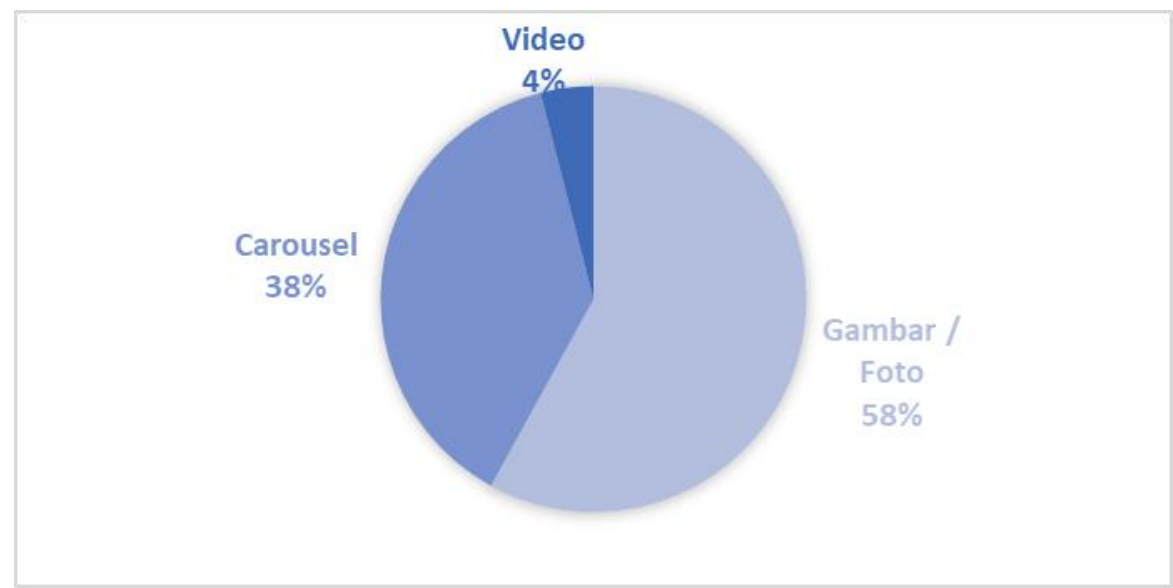

Gambar 6. Unggahan Konten Flip di Instagram

Berdasarkan hasil analytical tools, konten yang diunggah oleh Flip di Instagram mayoritas adalah berbentuk gambar / foto, selanjutnya berbentuk carousel. Carousel dalam Instagram adalah pin yang berisi beberapa gambar yang biasanya bertujuan untuk memamerkan berbagai fitur produk, mengiklankan beberapa produk sekaligus, atau menceritakan brand kita dalam beberapa bab. Fitur ini dapat sekaligus mengunggah hingga 10 foto, video ataupun gabungan foto dan video. Sedangkan konten yang paling sedikit diunggah oleh Flip adalah yang 
berbentuk video. Engagement yang terbangun untuk unggahan gambar sejumlah 1,407, carousel sebanyak 640 dan video 222. Dari sini bisa disimpulkan bahwa sebenarnya audiens Flip memiliki ketertarikan yang tinggi terhadap konten yang berbentuk video.

Waktu unggah yang optimal rata - rata terjadi pada jam pagi pukul 09.00 WIB sampai pukul 19.00 WIB. Panjang unggahan yang optimal adalah lebih dari 1121 karakter. Untuk tagar atas semua tagar Flip memiliki rata - rata engagement 7,191 jadi tidak ada yang lebih unggul. tagar yang optimal adalah memunggah dengan lebih dari 10 tagar (berdasarkan engagement). Hari yang paling tepat untuk membuat engagement kepada audience menurut hasil adalah hari Kamis, Sabtu serta hari Senin.

Sedangkan untuk platform media sosial Twitter, berdasarkan analytic tools Keyhole didapatkan data bahwa Flip cukup aktif selama peridoe Januari - Maret 2020 dengan jumlah unggahan sebanyak 232 unggahan, namun engagement yang terjadi sangat rendah yaitu hanya $0,09 \%$ dengan jumlah likes dan retweet yang sangat minim. Hal ini sangat berbeda jauh dengan Instagram yang memiliki engagement cukup tinggi. Rata - rata total unggahan paling banyak terjadi pada bulan Maret sebanyak 133 post. Engagement paling tinggi bulan januari dengan angka 2 dari range $0-2,1$. Total likes dan retweet adalah 0 . Top post by engagement adalah mengenai informasi atau kabar terbaru tentang Flip. Tipe unggahan paling sering secara berturut-turut adalah Reply sebanyak $81 \%$, Retweet sebanyak $8 \%$, Text sebanyak $7 \%$ dan Quote sebanyak 3\%.

Menurut Analytical Tools Facebook, @hai_flip memiliki data harian yang diambil pada April 2020 bahwa overall score dan performance FB Flip mendapatkan nilai B- dengan jumlah peningkatan rata-rata Like setiap harinya adalah +3 Like dan data jumlah peningkatan rata-rata Like setiap harinya -1 Like (data dari tgl 3 bulan April 2020). Jumlah Total Page Likes Flip hingga April 2020 adalah sebanyak 15.817, Total Talking About Flip sebanyak 27,921.

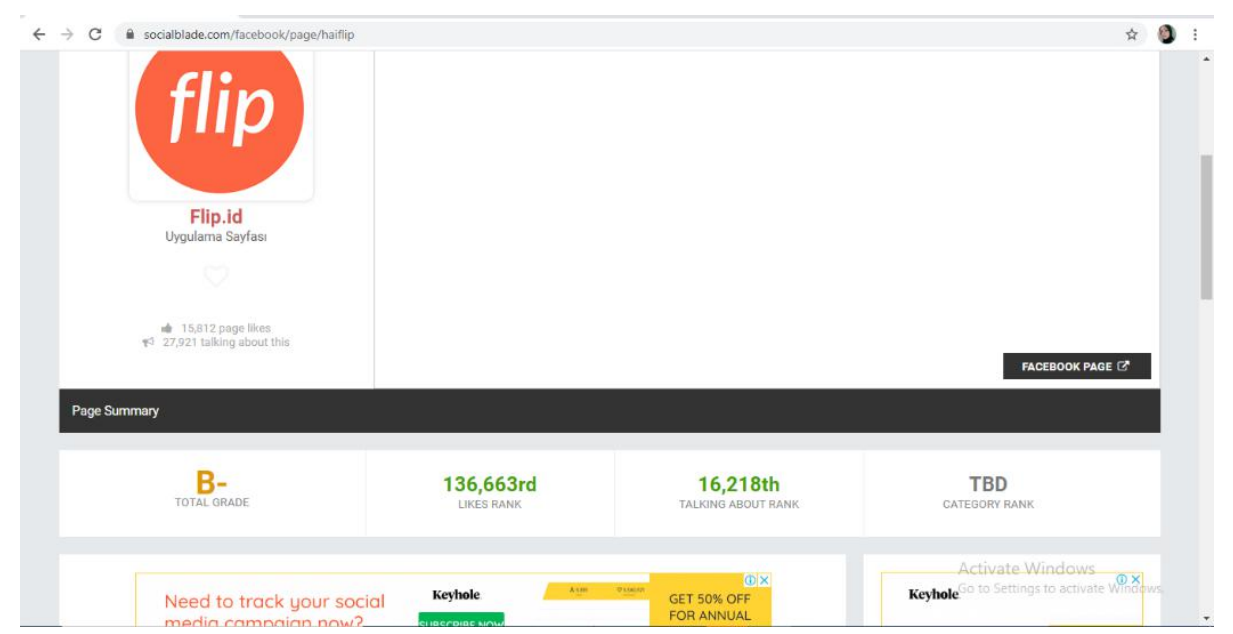

Gambar 7. Hasil Analytical Tools Flip untuk Platform Facebook

Aktivitas online yang dilakukan Flip untuk membangun engagement ke target audiens dimetaforakan selayaknya pertemanan. Flip sering menyapa target market dengan bahasa informal dan hangat dan berusaha hadir sebagai teman mereka, bukan sebagai orang yang ingin mengambil keuntungan sebanyak banyaknya. Teman yang baik adalah teman yang dapat memberi manfaat, oleh karenanya Flip rutin menghadirkan konten yang membawa manfaat untuk target audiens mereka, rajin membalas setiap komentar dan pesan, dan mengajak mereka berinteraksi di segala jenis unggahan.

Flip saat ini juga bekerja sama dengan Social Media Influencer (SMI) berupa Micro Influencer yaitu mereka yang punya expertise atau keahlian di bidang keuangan dengan follower yang segmented, yang berarti jumlah followernya tidak terlalu banyak dan tidak terlalu sedikit. Bagi Flip, Micro Influencer adalah orang-orang yang vision \& impact oriented, selain itu mereka benar benar paham apa yang mereka ucapkan tentang Flip. Bukan sekedar copy-paste 
tanpa cek. Mereka juga punya gaya unik tersendiri dalam berkomunikasi. Dari segi investasi, bekerja sama dengan Makro Influencer biasanya tidak terlalu mahal, bahkan terkadang free of charge alias gratis.

Dengan keterbatasan sumber daya yang dimiliki, Flip masih melakukan social media monitoring secara manual dengan mencari secara manual berdasarkan keyword di media sosial masing masing. Oleh karena itu Flip merasa mereka masih belum efektif dalam membangun digital presence melalui website dan media sosial. Kendala-kendala yang dihadapi antara lain tentang konsistensi dan keseragaman dalam tampilan visual. Ke depannya Flip memiliki rencana untuk berinvestasi dengan menggunakan analytical tools tersendiri untuk bisa lebih memudahkan pekerjaan.

Dari penelitian yang dilakukan selama bulan Januari hingga Maret 2020, ditemukan berbagai kelebihan dan kelemahan dalam pengelolaan website dan media sosial milik Flip. Kelebihan dari website dan media sosial Flip dapat dilihat dari graphic design-nya yang memiliki tone and manner yang konsisten. Dalam menyampaikan informasinya pun, Flip menggunakan bahasa yang informal sehingga membuat pengikut sosial medianya merasa lebih akrab. Flip menggunakan beragam media sosial yang dapat mencakup seluruh pengguna Flip. Karena belum tentu semua pengguna Flip menggunakan media sosial yang sama. Konten yang diberikan oleh Flip sebagian besar berisi konten informatif dan berguna.

Sedangkan untuk kekurangan, Flip cenderung tidak konsisten dan rutin dalam memunggah kontennya, Flip juga kurang interaktif kepada pengikutnya terutama pada media sosial Facebook. Contohnya, Flip jarang membalas pesan yang ditulis oleh pengguna Flip di halaman Facebook Flip. Dan di Twitter, saat admin Flip membalas pesan yang diberikan pengikutnya tidak menuliskan nama atau identitas admin yang sedang bertugas. Selain itu, masih banyak orang yang merasa cukup resah dan bingung dengan maksud dari kode unik, apakah kode unik akan merugikan konsumen? karena sebagaimana dengan klaim yang dikatakan Flip, Flip tidak memungut biaya admin dalam proses transaksinya. Mengingat core business Flip berkaitan erat dengan uang, kesigapan respon customer service Flip dalam merespon keluhan ataupun pertanyaan pengguna Flip sepertinya perlu ditingkatkan karena dapat menimbulkan kecemasan penggunanya yang jika dibiarkan akan berakibat pada review buruk dari pengguna yang berpengaruh langsung pada reputasi Flip.

\section{SIMPULAN}

Flip sebagai start-up lokal di industri FinTech menyadari bahwa saat ini komunikasi berperan penting dalam sustainability bussiness. Saat ini Flip telah memiliki website dan berbagai media sosial media tidak hanya untuk menyampaikan segala sesuatu yang baru tentang produk mereka, namun juga untuk membentuk mutual understanding melalui percakapan-percakapan yang dibangun di berbagai platform yang digunakan. Oleh karena itu Flip ingin membangun digital engagement dimana user dapat berinteraksi dengan mereka di media sosial sekaligus mendapatkan manfaat berupa keilmuan dasar seputar dunia finansial, beragam tip keuangan yang lekat dengan keseharian mereka, serta menjalin hubungan dan kedekatan yang bersifat jauh lebih personal antara Flip sebagai perusahaan dengan target audiens mereka. Dengan segala keterbatasan sumber daya, Flip berusaha untuk konsisten dengan brand identity mereka yang khas dengan warna orange dan putih dalam tampilan website dan media sosial yang digunakan.

Website Flip bertujuan untuk memberikan informasi - informasi seputar penggunaan aplikasi Flip seperti cara penggunaan, cara kerja transfer, hingga nama - nama bank apa saja yang sudah bekerja sama dengan Flip. Di dalam website, tergambar dengan jelas alur transaksi saat menggunakan Flip. Website Flip juga menyertakan pertanyaan serta jawaban yang mungkin sering diajukan oleh konsumen Flip. Pertanyaan serta jawaban tersebut masuk ke dalam section FAQ (Frequently Asked Question). Berdasarkan analytical tools, peringkat 
website flip.id telah meningkat $32 \%$ selama 3 bulan terakhir (Januari - Maret 2020) dengan mencapai sekitar 63.330 pengunjung dan 139.350 hits setiap bulan. Secara garis besar kontenkonten yang mendapatkan engagement tertinggi antara lain giveaway, tips dan challenge dan di antara semua media sosial yang digunakan Flip, Instagram memiliki rata-rata engagement tertinggi yaitu mencapai $60 \%$.

Dalam berbagai aktivitas online yang dilakukan Flip untuk membangun engagement ke target audiens dimetaforakan selayaknya pertemanan. Flip sering menyapa target audiens dengan bahasa informal dan hangat dan berusaha hadir sebagai teman mereka dengan memberi manfaat sebanyak mungkin. Flip sendiri juga bekerja sama dengan Social Media Influencer (SMI) berupa Micro Influencer yaitu mereka yang punya expertise atau keahlian di bidang keuangan dengan follower yang segmented dan terbukti cukup efektif dalam membangun engagement di platform yang mereka gunakan.

\section{DAFTAR PUSTAKA}

Arner, D. W., Barberis, J., \& Buckley, R. P. (2015). The evolution of FinTech: A new post-crisis paradigm. Geo. J. Int'l L., 47, 1271.

Avery, E. J., \& Graham, M. W. (2013). Political public relations and the promotion of participatory, transparent government through social media. International Journal of Strategic Communication, 7(4), 274-291. doi:10.1080/1553118X.2013.824885.

Botan, C. H., \& Taylor, M. (2004). Public relations: State of the field. Journal of Communication, 54(4), 645-661. doi:10.1111/j.1460-2466.2004.tb02649.x

Boyle, E. (2003). A study of entrepreneurial brand building in the manufacturing sector in the UK. Journal of Product \& Brand Management, 12, 79-93.doi:10.1108/10610420310469779

Bresciani, S., \& Eppler, M. J. (2010). Brand new ventures? Insights on start-ups' branding practices. Journal of Product \& Brand Management.

Chen, Z. F., Ji, Y. G., \& Men, L. R. (2017). Strategic Use of Social Media for Stakeholder Engagement in start-up Companies in China. International Journal of Strategic Communication, 11(3), 244-267. https://doi.org/10.1080/1553118X.2017.1298114

Devin, B. L., \& Lane, A. B. (2014). Communicating engagement in corporate social responsibility: A meta-level construal of engagement. Journal of Public Relations Research, 26(5), 436-454. doi:10.1080/1062726X.2014.956104

Heath, R. L. (2006). Onward into more fog: Thoughts on public relations' research directions. Journal of Public Relations Research, 18(2), 93-114. doi:10.1207/s1532754xjprr1802_2

Heath, R. L. (2014,May). Public relations' role in engagement: Functions, voices, and narratives. Paper presented at the Engagement as strategy, theory and practice. ICA preconference 2014, Seattle, WA.

Ji, Y. G., Li, C., North, M., \& Liu, J. (2015). Staking reputation on stakeholders: How does stakeholders' Facebook engagement help or ruin a company's reputation? Public Relations Review 41(1), 201-215. doi:10.1016/j.pubrev.2016.12.004bk_AQCmts12b

Khan, G. F. (2017). Social media for Government. Springer Books.

Kriyantono, R. (2020). Teknik Praktis Riset Komunikasi. Jakarta: Kencana Prenada Media Group

Li, Y., Spigt, R., and Swinkels, L., (2017). The Impact of FinTech Start-Ups on Incumbent Retail Banks' Share Prices, Financial Innovation, 26, 1-16.

Lovejoy, K., Waters, R. D., \& Saxton, G. D. (2012). Engaging stakeholders through Twitter: How nonprofit organizations are getting more out of 140 characters or less. Public relations review, 38(2), 313-318

Narayan, S., Sahminan, S., (2018). Has FinTech Influenced Indonesia's Exchange Rate and Inflation? Bulletin of Monetary Economics and Banking (Buletin Ekonomi Moneter dan Perbankan), 21, 303-322 
Natalia, D., \& Shihab, M. (2018). Public Relations Strategies to Built Financial Technology (FinTech) Awareness The IKoinworksr Way. 260(Icomacs), 254-257. https://doi.org/10.2991/icomacs-18.2018.62

Yin, R. K. (2006). Studi kasus: desain dan metode. Raja Grafindo Persada. Jakarta.

https://flip.id/ 